\title{
Legal Constraints and Analysis of College and University Students' Behavior in the Network Environment
}

\author{
Dongyu Zhao ${ }^{1} \& \mathrm{Hui}^{1}{ }^{1}$ \\ ${ }^{1}$ Qingdao University of Science and Technology, Qingdao, China \\ Correspondence: Dongyu Zhao, No.99 Songling Road, Qingdao University of Science and Technology, Qingdao \\ 266061, China. Tel: 86-532-8895-8268. E-mail: zdyhao@126.com
}

Received: January 24, 2015 Accepted: January 31, 2015 Online Published: February 13, 2015

doi:10.5539/jpl.v8n1p35

URL: http://dx.doi.org/10.5539/jpl.v8n1p35

The author would like to acknowledge the support by the 2014 Qingdao University of Science and Technology human and social science program (No.13XB28,) and the 2014 Qingdao Social Science Planning Project (No.QDSKL1401061).

\begin{abstract}
The network has become an important channel for current college and university students to exchange information and communication, and become an important part of University life. Although college and university students very like network but most college and university students cannot use the network effectively. Network with its openness and vitality also makes some college and university students freely, lack of moral self-discipline in the network environment. More and more college and university students pay attention to the protection of their rights in the network environment, but a few college and university students have unconsciously infringe upon the rights of other people. So, universities need to carry out effective rule of law education and morality education for University students. Countries should strengthen the network legislation; regulate the constraints on the network infringement and cyber crime. At the same time, we should purify network environment through technical means and help college and university students grow up healthily in the network environment.
\end{abstract}

Keywords: network environment, behavior analysis, legal constraints

\section{Introduction}

Network as a new media, has become an important channel for the current college and university students to exchange information and communication, the influence of college and university students has gone deep into all aspects of life. But the network environment unique openness, autonomy and diversity will bring negative effect to the network behavior of College and university students. Therefore, some people think that the network is a "double-edged sword". However, the popularity of the network has already become irresistible. The important thing is how to guide college and university students to set up correct network moral values, to promote their network moral self-discipline. Colleges and universities should strengthen the students guide in network moral education for college and university students in view of psychological stress and negative influence. At the same time, we should also be timely intervention and counseling for the unhealthy network behavior. Our aim should be to make every student really learn to navigate the network, draw nourishment from the network. At present, colleges and universities should know more about the current students' network moral situations. Strengthen the network moral education and legal education of college and university students has become an important part in colleges and universities. So it is important to research college and university students' behaviors in the network environment and carry out law education and moral education according to these behaviors in current China.

\section{Analyses of College and University Students' Behavior in the Network Environment}

\subsection{College and University Students Enjoy Network Life But Most of Them Cannot Use Network Effectively}

According to a investigation of college and university students' behaviors in the network environment from some universities in Qingdao Area in China: network has become an indispensable content in university students' life. Almost all of the students have experienced the network. They spend some time on Internet: $50 \%$ of the college and university students spend 1-2 hours on the Internet; $30 \%$ of the college and university students spend $2-3$ 
hours on the Internet; $18 \%$ of the college and university students spend more than 3 hours every day on the Internet. Although so many college and university students like network very much, but most college and university students cannot use network effectively. In answer to "what is the main purpose that you use network"? $61 \%$ of the college and university students choose the answer as "watching movies, listening to music, playing games, leisure and entertainment"; $17 \%$ of the students choose the answer as "chat with friends"; $9 \%$ of the college and university students choose the answer as "search data or learning"; $8 \%$ of the college and university students chose the answer as "shopping"; $5 \%$ of the college and university students' answer is "for other purpose ".From the survey we can see that only $9 \%$ of college and university students who really use the network to enrich themselves knowledge, $91 \%$ of the college and university students cannot use the network effectively.

\subsection{Some College and University Students Are Lack Moral Self-discipline in the Network Environment}

The convenience of the network broke the communication space constraints between people; anyone can through the network to communicate with the outside world at any time. At the same time, the network has the Characteristics of openness, convenient also make some college and university students in the network environment is follow one's inclinations, lack of moral self-discipline. Some college and university students demonstrated swearing, browsing pornographic sites, the presence of a small amount of internet plagiarism behavior. According to one survey of university students' behaviors in the network environment in Qingdao area in China: when some college and university students been asked "if you say bad words in the network environment?", $2 \%$ of the surveyed students answer "often say bad words"; $30 \%$ of the surveyed students choose the answer as "occasionally say bad words"; $10 \%$ of the surveyed students choose the answer as "when the others person say bad words, I will swearing revenge on him"; $58 \%$ of the surveyed students choose the answer as "never say bad words". Despite the frequent swearing students accounted for only $2 \%$, but in the network environment due to the convenient and widespread dissemination of information, the author worry that this will also bring adverse effect, this part of the college and university students should restrain them not to say bad words, striving to be civilized citizens. For the problem as "do you often visit porn sites", $82 \%$ of the surveyed college and university students answer that they have never visited porn web content; $13 \%$ of the college and university students admitted that they occasionally visit "Browse" porn sites; $5 \%$ of the surveyed college and university students answer that they often browse pornographic websites. For the $5 \%$ of the surveyed college and university students who often visit "Browse" porn sites, the author are deeply worry about this. Why this phenomenon should occur? One reason is these college and university students in the special physiological age and psychological stages, another reason is that the network environment has the Characteristics of openness and lack of constraints .so some college and university students are lack moral self-discipline in the network environment.

\subsection{College and University Students Are Good at Protecting Their Rights in the Network Environment}

More and more college and university students are good at protecting their rights in the network environment. When they are asked how they consider the network real name system, up to $58 \%$ of the surveyed college and university students agree with network real name system; $28 \%$ of the surveyed college and university students choose the answer that they do not agree with it; $14 \%$ of the surveyed college and university students have no idea about this problem. In order to standardize the behaviors in the network environment, most surveyed college and university students are willing to carry out network real name system. According to the problem "if you need to fill in information for registration in the network environment, do you fill in real information?", $36 \%$ of surveyed college and university students select the answer "I fill in real information"; only 7\% of surveyed college and university students select the answer "I never fill in real information"; the remaining 57\% of surveyed college and university students choose the answer " I will first consider the situation and then decide whether or not to fill in real information". This reflects that most college and university students are good at protecting their rights in the network environment.

2.4 Some College and University Students in the Network Environment Are Unconsciously Infringe on the Other Rights

However, the majority of college and university students are paying attention to self-protection, but they do not know how to protect the rights of others, sometime they are unconsciously infringe upon the rights of other people. For example, in the network environment, some college and university students are interested in others secrets and try to find out. Of course, most college and university students maybe don't do so, but $14 \%$ of surveyed college and university students choose the answers as "I will find out the others secret" This make us worry. Some surveyed college and university students participate in the unfamiliar person pork search in. This 
inadvertently violating the rights of others, however, they do not know it is illegal. As the question "how do you see the network hacker", $65 \%$ of the surveyed college and university students answered that "hackers have high technology, they are very powerful". $31 \%$ of the surveyed college and university students answer as "I worship hackers, but they can approach problems". There is $4 \%$ of the surveyed college and university students consider that "hackers are bad guys". Through these research results we can conclude that minority college and university students do not know how to respect and protect the legitimate rights of others, and even some college and university students are infringing on other rights in the network environment .At the same time, some college and university students have Internet plagiarism, network deception problems. Therefore, the strengthening of the rule of law education for college and university students in the network environment is important.

\section{Countermeasures and Suggestions}

\subsection{We Need to Strengthen the Legal Constraints in the Network Environment}

Chinese Internet information construction and management has made some achievements after more than 10 years of history, but there are still legal system is not perfect, the standard is not unified, network tort events is difficult to stop such current situation on the whole. Therefore, there has a long way to go to strengthen the network construction and management; we should constraint the rules of network behaviors. In February 1996, the State Council promulgated the Computer Information Network and the Management Interim Provisions, they management with highest efficiency regulations, the other major regulations as Chinese Public Computer Internet Interconnection Management Approach , Chinese Public Multimedia Communication, "Computer Information Network and the Internet Security Protection and Management Measures etc.. However, network legislation work at present with respect to the network crime is increasingly serious lags; effectively prevent the occurrence of network crime. It is necessary to further strengthen the China network legislation work, thereby reduce the occurrence of network infringement events and network crime in the network environment.

\subsection{College and University Students should be Given Effective Morals Education in the Network Environment}

First of all, the university should be included in the specification of the network behavior will education into the classroom teaching process, and through the network behavior of college and university student real case education of college and university students in the network world conventions fan's own words and deeds. Secondly, colleges and universities can be organized to carry out a series of network morality as the theme of the publicity and education activities, such as seminars, debate, speech contest, forums and other activities related. We should enable college and university students to understand themselves behavior and others' in the network environment, to reduce the occurrence of the network immoral behavior and infringement events. Through the development of moral education for a long time, impel students to establish the correct network morality.

\subsection{Government should Purify Network Environment with Technical Means and Help College and University Students Grow up Healthily in Network Environment}

Government should purify network environment with technical means and help college and university students grow up healthily in network environment .On one hand, the network environment is open, virtual, secrecy and many other features. These characteristics determine the network culture is an open culture. A variety of culture and ideas will be faced with the popularization of the network presented in college and university students. That may lead college and university student moral consciousness, even to moral crisis. On the other hand, the characteristics virtual property and secrecy of the network also make college and university students bring their true identity hidden in the network world. College and university students are difficult to form subject to external norms "heteronymous morality", so that many students make some network immoral behaviors. Network monitoring and Management Department of the government and the school to cope with yellow web, other harmful website to monitor, to build a "firewall" on the Internet, various garbage information interception, let college and university students have a healthy network environment. To the campus network infrastructure optimization, set up more advanced monitoring software and monitoring technology, the use of technical means, to the campus network pornography, violent, reactionary illegal data packet filter, intrusion effectively guard against external negative information, purification College of Internet environment, let college and university students grow up healthily in the civilized environment.

\subsection{The College and University should Strengthen Students' Psychological Counseling, to Reduce Their Psychological Problems in Network Environment}

College and university students are in the special period, their psychological development is not fully mature, the lack of social experience, poor ability to adapt, and self-control is relatively limited. These are easy to cause college and university students affected by the outside world. Some college and university students are too 
obsessed with the network, have a psychological dependence to the network, it will cause them to the reality of lack of emotional communication and cold, then causes them to produce anxiety from the Internet, Internet addiction disorder and other psychological problems. At present, many college and university students have problems in cognition, emotion indifferent, fuzzy honesty loss in the network environment. These problems, as there are many reasons of the students themselves, there are also reasons of social environment of profound. We should pay attention to these problems and take active measures. For college and university students, as an important force in the future national construction, they can grow up healthily in the network environment, directly related to the future of the country. Students should strengthen the moral self-discipline, the key lies in each college and university students to study and introspection. Colleges and universities should strengthen psychological counseling for students, strengthen communication with students exchange with the campus network, micro blog, chat rooms, forums and other network carrier, solve the psychological perplexity of college and university students, at the same time the use of the face of psychological counseling and psychological therapy face. We should find out the root of college and university students' psychological problems, and then carry out targeted education and guidance, thus we can reduce the psychological pressures and psychological discomforts which the network brings to college and university students .Colleges and universities should also take more measures to timely intervention and reduce unhealthy network moral behaviors.

\section{Conclusions}

1) College and university students enjoy network life, most of them cannot use network effectively. They should be constrained and guided in the network environment. College and university should strengthen students' psychological counseling, to reduce their psychological problems in network environment.

2) Some college and university students have ability of self-protection; they are unconsciously infringing on others rights. It is important to research college and university student's behaviors in the network environment and according to that to carry out rules of law education and moral education for college and university students in the current China.

3) We should strengthen the China network legislation; restrict college and university students' behaviors in the network environment, thereby reducing the occurrence of network infringement events and network crime. It is necessary to further strengthen the China network legislation work, thereby reduce the occurrence of network infringement events and network crime in the network environment.

4) Government should purify network environment with technical means and help college and university students grow up healthily in network environment.

\section{References}

Deng, Y., \& Li, Z. (2008). Discussion on the Network Moral Education of College Students. Journal of Higher Education Research, 6, 89-90. Retrieved from http://www.cqvip.com/read/read.aspx?id=27536847

Guo, X. (2007). Reconstruction and Lack of College Students Network Moral Personality. Journal of Jiangsu Higher Education, 5, 105-106. Retrieved from http://www.cqvip.com/read/read.aspx?id=25313674

Li, C. (2012). Governance of Internet Morality Anomie of College Student. Journal of Tianjin Manager College, 1, 62-63. Retrieved from http://www.cqvip.com/read/read.aspx?id=40862211

Qiu, J. (2009). Moral Problems, Causes and Countermeasures of College Student in the Network Environment. Journal of Ideological and Political Education Research, 1, 37-40. Retrieved from http://www.cqvip.com/read/read.aspx?id=29642113

Wang, Y. (2012).Study on Countermeasures of Morality of College Students in the Network Environment. Journal of Economic Research Guide, 1, 311-312. Retrieved from http://www.cqvip.com/read/read.aspx?id=40486054

Wang, Y., Ding, Z., Chen, H., \& Gao, X. (2009). Analysis and Countermeasures of Education on Network Moral Situation of College and University Students. Journal of School Party Construction and Ideological Education, 10, 73-75. Retrieved from http://www.doc88.com/p-9909423132947.html

Xu, X. (2012). Research on Standard System of College Students' Network Morality Construction. Journal of Shenyang Agricultural University (Social Sciences Edition), 7, 446-449. Retrieved from http://www.cqvip.com/read/read.aspx?id=44045549

Xue, W., \& Liu, Q. (2011). An Investigation and Analysis of Network Moral Status of the Undergraduates. Journal of Liaoning Normal University (Social Science Edition), 3, 58-60. Retrieved from http://www.cqvip.com/read/read.aspx?id=37034493 
Zhao, H. (2012). Investigation on the Psychological and Behavior of College Students in the Network Environment, Master of Shenyang University of Aeronautics and Astronautics. Retrieved from http://cdmd.cnki.com.cn/Article/CDMD-10143-1012317035

\section{Copyrights}

Copyright for this article is retained by the author(s), with first publication rights granted to the journal.

This is an open-access article distributed under the terms and conditions of the Creative Commons Attribution license (http://creativecommons.org/licenses/by/3.0/). 